\title{
MicroRNA-218 inhibits the cell proliferation and migration in clear cell renal cell carcinoma through targeting cancerous inhibitor of protein phosphatase $2 \mathrm{~A}$
}

\author{
RUOJING WEI ${ }^{1}$, XIONGJUN YE $^{2}$, YAWEI ZHAO ${ }^{1}$, NING JIA ${ }^{3}$, TONGWEI LIU ${ }^{1}$, \\ WENFENG LIAN ${ }^{1}$, HONGJIAN WEI $^{1}$, GANG ZHANG $^{1}$ and LIJIE SONG ${ }^{1}$
}

\author{
${ }^{1}$ Department of Urology, The First Central Hospital of Baoding, Baoding, Hebei 071000; ${ }^{2}$ Department of Urological Surgery, \\ Beijing University People's Hospital, Beijing 100044; ${ }^{3}$ Department of Digestive Endoscopy Center, \\ The Affiliated Hospital of Hebei University, Baoding, Hebei 071000, P.R. China
}

Received April 7, 2018; Accepted January 4, 2019

DOI: $10.3892 / \mathrm{ol} .2019 .9986$

\begin{abstract}
MicroRNAs (miRs) have emerged as critical modulators of tumor initiation and progression in numerous types of human cancer, including clear cell renal cell carcinoma (ccRCC), which is the most common subtype of renal cell carcinoma. Cancerous inhibitor of protein phosphatase 2A (CIP2A) is a newly characterized oncoprotein and its overexpression has been reported to promote cellular epithelial-mesenchymal transition and the tumor progression of ccRCC. The present study examined the effects of miR-218 on CIP2A expression in ccRCC cells. The results demonstrated that the expression level of miR-218 was lower in ccRCC tissues compared with that in adjacent non-tumor renal tissues. In addition, it was identified that miR-128 could directly bind to the 3'-untranslated region of CIP2A. Furthermore, a negative correlation between the expression levels of miR-218 and CIP2A was detected in ccRCC. Additionally, the downregulation of CIP2A or overexpression of miR-218 in ccRCC cells was revealed to inhibit cell proliferation and migration. In summary, these data suggest that miR-218 serves a role in the regulation of CIP2A and elucidate its consequences on tumor progression, tumor cell proliferation and migration. These results indicate that miR-218 may exhibit potential as a molecular target for the treatment of ccRCC.
\end{abstract}

\section{Introduction}

Renal cell carcinoma (RCC) is the second most commonly diagnosed cancer type in human urological systems and

Correspondence to: Dr Ruojing Wei, Department of Urology, The First Central Hospital of Baoding, 320 North Greatwall Street, Lianchi, Baoding, Hebei 071000, P.R. China

E-mail: weiruojing_dr@163.com

Key words: microRNA-218, cancerous inhibitor of protein phosphatase $2 \mathrm{~A}$, clear cell renal cell carcinoma, tumor suppressor accounts for almost $3 \%$ of all adult malignancies (1). Clear cell renal cell carcinoma (ccRCC) is the most common type of RCC and accounts for 70-80\% of all occurrences of RCC (2). At the time of diagnosis, $33 \%$ of patients with ccRCC have distant metastases, which makes it difficult or occasionally impossible to perform surgery (3). In addition, treatment strategies for metastatic ccRCC are limited, as it is often resistant to chemotherapy and radiotherapy (4). Therefore, biomarkers that can assist with early diagnosis or prognosis prediction are urgently required.

MicroRNAs (miRNAs/miRs) are a class of small non-coding RNAs that regulate gene expression at the post-transcriptional stage (5). It is understood that this process is mediated via direct binding to the 3'-untranslated region (UTR) of target mRNA transcripts (6). The value of miRNAs in the diagnosis or treatment of ccRCC has received considerable attention (7). Detection of aberrantly expressed miRNAs can distinguish ccRCC from normal tissue and predict the prognosis of patients with ccRCC $(8,9)$.

miR-218 is a vertebrate-specific intronic miRNA and the gene that encodes miR-218 is located at the introns of tumor suppressor slit guidance ligand (SLIT)2 and SLIT3 (10). Previous studies have demonstrated that the expression of miR-218 is significantly reduced in numerous types of human cancer, including colorectal cancer (11), breast cancer (12), gastric cancer (10), non-small cell lung cancer (13) and ovarian cancer (14), which suggests that miR-218 can function as a tumor suppressor. Reduced expression of miR-218 was associated with advanced tumor stage and lymph node metastasis in ovarian cancer, and restoration of miR-218 expression levels inhibited cell proliferation, migration and invasion in vitro by targeting runt-related transcription factor 2 (14). Another study demonstrated that miR-218 serves as a tumor suppressor in lung cancer by targeting interleukin-6/signal transducer and activator of transcription 3, and that it negatively correlates with a poor prognosis (15). However, to the best of our knowledge, the expression status and the mechanism by which miR-218 exerts its clinical significance in ccRCC remain largely unknown. 
Therefore, the present study was aimed to investigate the expression of miR-218 in ccRCC. In addition, the biological roles of miR-218 on proliferation and migration were examined. In addition, the downstream target of miR-218 was examined by bioinformation analysis tool and western blot analysis. The present study provided a novel insight into the mechanism of ccRCC tumor progression and identified a novel biomarker for ccRCC treatment.

\section{Patients and methods}

Patients and tissue samples. A total of 43 patients (mean age, 56.7; range, $42-73$ years old) with ccRCC treated at The First Central Hospital of Baoding (Baoding, China) between January 2011 and October 2012 were enrolled in the study. Paired tumor and normal tissues ( $\geq 2 \mathrm{~cm}$ from the tumor) were obtained from these patients, immediately snap-frozen in liquid nitrogen and stored at $-80^{\circ} \mathrm{C}$ until further use. Informed written consent was obtained from all patients who participated in the study. The study procedure was approved by the Ethics Committee of The First Central Hospital of Baoding. Clinicopathological features were obtained and their associations with the expression level of miR-218 are summarized in Table I.

Cell culture. The human RCC Caki-1 and 786-O cell lines, and the immortalized proximal tubule epithelial HK-2 cell line were purchased from the American Type Culture Collection (Manassas, VA, USA). These cell lines were maintained in Dulbecco's modified Eagle's medium supplemented with $10 \%$ fetal bovine serum (both Invitrogen; Thermo Fisher Scientific, Inc., Waltham, MA, USA), $100 \mathrm{U} / \mathrm{ml}$ penicillin and $100 \mathrm{U} / \mathrm{ml}$ streptomycin. The cell lines were incubated in a humidified incubator containing $5 \% \mathrm{CO}_{2}$ at $37^{\circ} \mathrm{C}$.

Cell transfection. The miR-218 mimic (5'-UGUACC AAUCUAGUUCGUGUU-3'), miR-218 inhibitor (5'-ACA UGGUUAGAUCAAGCACAA-3') and negative control (NC, 5'-UCACAACCUCCUAGAAAGAGUAGA-3') were designed and synthesized by Guangzhou RiboBio Co., Ltd. (Guangzhou, China). Small interfering RNA (siRNA) targeting CIP2A (si-CIP2A) and NC siRNA were also synthesized by Guangzhou RiboBio Co., Ltd. Lipofectamine ${ }^{\circledR}$ 2000 (Invitrogen; Thermo Fisher Scientific, Inc.) was used for transfection of the miRNAs $(100 \mathrm{nM})$ or siRNAs into Caki-1 and 786-O cell lines, according to the manufacturer's protocols. Cells were harvested for the following experiments following transfection for $48 \mathrm{~h}$.

Cell proliferation assay. An MTT assay was conducted to investigate the cell proliferation ability. Briefly, Caki-1 and 786-O cells transfected with or without miRNAs or siRNAs were seeded at a density of $3 \times 10^{3}$ cells/well in a 96-well plate and incubated for $0,24,48$ or $72 \mathrm{~h}$ at $37^{\circ} \mathrm{C}$. Subsequently, $20 \mu \mathrm{l}$ MTT $(5 \mathrm{mg} / \mathrm{ml})$ was added to each well and further incubated for $4 \mathrm{~h}$. Following the removal of supernatant, $100 \mu \mathrm{l}$ dimethyl sulfoxide (Sigma-Aldrich; Merck KGaA, Darmstadt, Germany) was added to stop the reaction. The optical density was measured with a microplate reader at a wavelength of $595 \mathrm{~nm}$.
Table I. Associations of miR-218 expression with the clinicopathological features of patients with clear cell renal cell carcinoma.

\begin{tabular}{lcccc}
\hline & \multicolumn{3}{c}{ miR-218 expression level } & \\
\cline { 3 - 4 } Variable & $\mathrm{n}$ & High $(\mathrm{n}=15)$ & Low $(\mathrm{n}=28)$ & P-value \\
\hline Sex & & & & 0.511 \\
$\quad$ Male & 22 & 7 & 15 & \\
Female & 21 & 8 & 13 & \\
Age, years & & & & 0.285 \\
$\geq 60$ & 20 & 8 & 12 & \\
$<60$ & 23 & 7 & 16 & \\
Tumor size, cm & & & & 0.029 \\
$\geq 5$ & 26 & 9 & 17 & \\
$<5$ & 17 & 6 & 11 & \\
Tumor stage & & & & \\
$\quad$ I-II & 15 & 5 & 10 & \\
III & 28 & 10 & 18 & \\
\hline
\end{tabular}

miR-218, microRNA-218.

Cell migration assay. A wound-healing assay was conducted to measure cell migration ability. Briefly, Caki-1 and 786-O cells transfected with or without miRNAs or siRNAs were seeded at a density of $2 \times 10^{5}$ cells/well in a 6 -well plate and incubated for $24 \mathrm{~h}$ at $37^{\circ} \mathrm{C}$. A wound was then created using a sterile $200-\mu 1$ pipette tip at the cell surface of each well. Subsequently, the cells were observed and the wound closure was quantified at 0 and $48 \mathrm{~h}$ following generation of the wound using Image J 1.42 software (National Institutes of Health, Bethesda, MA, USA).

3'-UTR luciferase reporter assay. The online prediction algorithm TargetScan (http://www.targetscan.org/) was used to predict the direct targets of miR-218. Among these potential targets, CIP2A was selected as it is recognized as an oncogene in human cancer (16). For the luciferase reporter assay, the wild-type and mutant 3'-UTR of CIP2A was cloned into psiCHECK-2 luciferase reporter vector (Promega Cooperation, Madison, WI, USA) and termed CIP2A WT and CIP2A MUT, respectively. Briefly, Caki-1 and 786-O cells were seeded at a density of $2 \times 10^{5}$ cells/well in a 24 -well plate. The cells were co-transfected with CIP2A WT or CIP2A MUT together with the miR-218 mimic or NC miRNA using Lipofectamine 2000 (Invitrogen; Thermo Fisher Scientific, Inc.). Luciferase activities were measured using the Dual-Luciferase Reporter Assay kit (Promega Cooperation) with Renilla luciferase activity as the internal control, following co-transfection for $48 \mathrm{~h}$, according to the manufacturer's protocol.

Reverse transcription-quantitative polymerase chain reaction $(R T-q P C R)$. Total RNA from tissue or Caki-1 and 786-O cells transfected with or without miRNAs or siRNAs was isolated using TRIzol ${ }^{\circledR}$ reagent (Invitrogen; Thermo Fisher Scientific, Inc.), according to the manufacturer's protocol. 

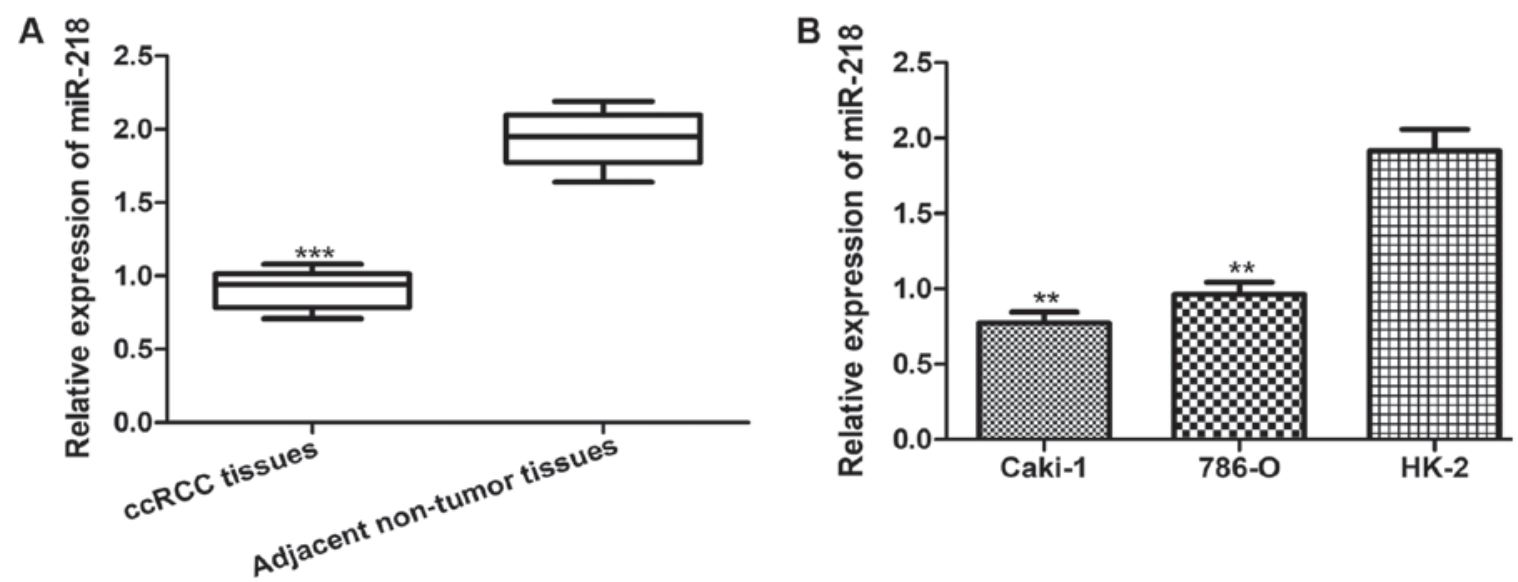

Figure 1. Expression level of miR-218 in clinical samples and various cell lines. (A) miR-218 expression levels were significantly lower in ccRCC tissues compared with those in adjacent normal tissues. ${ }^{* * * *} \mathrm{P}<0.001$ vs. adjacent non-tumor tissues. (B) miR-218 expression levels were significantly reduced in the Caki-1 and 786-O cell lines compared with those in the HK-2 cell line. ${ }^{* *} \mathrm{P}<0.01$ vs. HK-2. Data are presented as the mean \pm standard deviation. miR-218, microRNA-218; ccRCC, clear cell renal cell carcinoma.

RNA quality was measured with a NanoDrop ND-1000 spectrophotometer (Thermo Fisher Scientific, Inc.). M-MLV Reverse Transcriptase (Promega Cooperation) was used to synthesize complementary DNA at the prepared buffer of $250 \mathrm{mM}$ Tris- $\mathrm{HCl}\left(\mathrm{pH} 8.3,25^{\circ} \mathrm{C}\right), 375 \mathrm{mM} \mathrm{KCl}, 15 \mathrm{mM}$ $\mathrm{MgCl} 2,50 \mathrm{mM}$ DTT. The expression levels of miR-19a-3p were determined using the miScript SYBR Green PCR kit (Qiagen GmbH, Hilden, Germany) using an ABI7500 system (Applied Biosystems; Thermo Fisher Scientific, Inc.). The thermocycling conditions were as follows: Initial denaturation at $95^{\circ} \mathrm{C}$ for $10 \mathrm{~min}$, followed by 40 cycles of denaturation at $95^{\circ} \mathrm{C}$ for $1 \mathrm{~min}$ and annealing/extension at $56^{\circ} \mathrm{C}$ for $1 \mathrm{~min}$. The following primer sequences were used: miR-218 forward, 5'-ACACTCCAGCTGGGTTGTGCTTGATCTAA-3' and reverse, 5'-CTCAACTGGTGTCGTGGAGTCGGCAATTCA GTTGAGACATGGTT-3'; and U6 small nuclear RNA (snRNA) forward, 5'-GCGCGTCGTGAAGCGTTC-3' and reverse, 5'-GTGCAGGGTCCGAGGT-3'. The relative gene expression levels were determined using the $2^{-\Delta \Delta \mathrm{Cq}}$ method (17). The U6 snRNA was used for normalizing the expression of miR-218.

Western blot analysis. Total protein from tissues and Caki-1 and 786-O cells transfected with or without miRNAs or siRNAs was isolated using radioimmunoprecipitation assay lysis buffer (Beyotime Institute of Biotechnology, Haimen, China). The concentration of protein was measured using a BCA protein assay kit (Beyotime Institute of Biotechnology). Subsequently, protein samples $(50 \mu \mathrm{g})$ were separated by $10 \%$ SDS-PAGE and then transferred to polyvinylidene difluoride membranes (EMD Millipore, Billercia, MA, USA). The membranes were blocked with $5 \%$ skimmed milk in Tris-buffered saline with $0.1 \%$ Tween-20 (TBS-T) at room temperature for $1 \mathrm{~h}$ and incubated with mouse primary antibodies against CIP2A (1:1,000; catalog no. ab128179; Abcam, Cambridge, UK) or $\beta$-actin $(1: 1,000$; catalog no. ab8226; Abcam) at $4^{\circ} \mathrm{C}$ for overnight. Following washing with TBS plus Tween-20, the membranes were incubated with goat anti-mouse horseradish peroxidase-conjugated secondary antibodies (1:2,000; catalog no. ab6789; Abcam) at room temperature for $4 \mathrm{~h}$. The protein band signals were developed

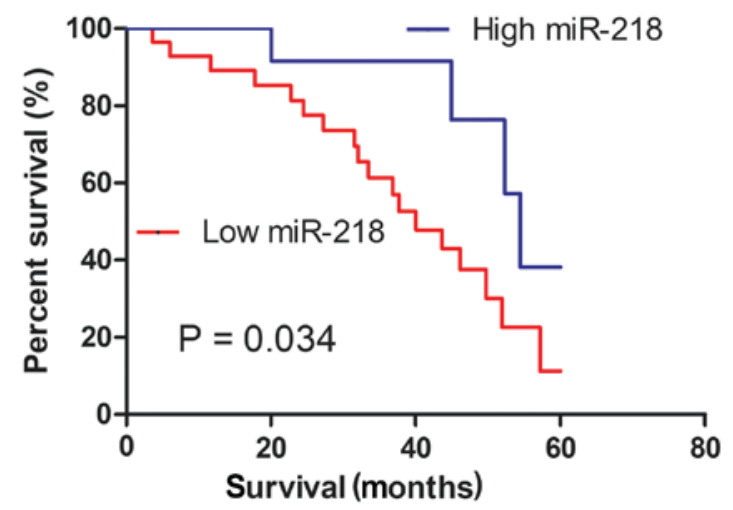

Figure 2. Kaplan-Meier curve for the 5-year overall survival rate of patients with low and high expression of miR-218. Patients with high miR-218 expression exhibited a significantly higher 5-year overall survival rate compared with those with low miR-218 expression. miR-218, microRNA-218.

using an enhanced chemiluminescence detection kit (Beyotime Institute of Biotechnology) and analyzed using Image J 1.42 software (National Institutes of Health).

Statistical analysis. Associations between the miR-218 expression level and clinicopathological parameters were evaluated using a $\chi^{2}$ test. An overall survival curve was plotted using the Kaplan-Meier method and a log-rank test. Correlations between miR-218 and CIP2A expression levels were assessed by Pearson's correlation coefficient method. All data are presented as the mean \pm standard deviation. Two groups were analyzed by paired Student's t-test, and three or more groups were analyzed by one-way analysis of variance followed by Tukey's post hoc test. Statistical analysis was performed using SPSS 16.0 software (SPSS, Inc., Chicago, IL, USA). P<0.05 was considered to indicate a statistically significant difference.

\section{Results}

Levels of miR-218 are frequently downregulated in ccRCC tissues and cell lines. To identify the role of miR-218 in the progression of ccRCC, miR-218 expression was examined in 

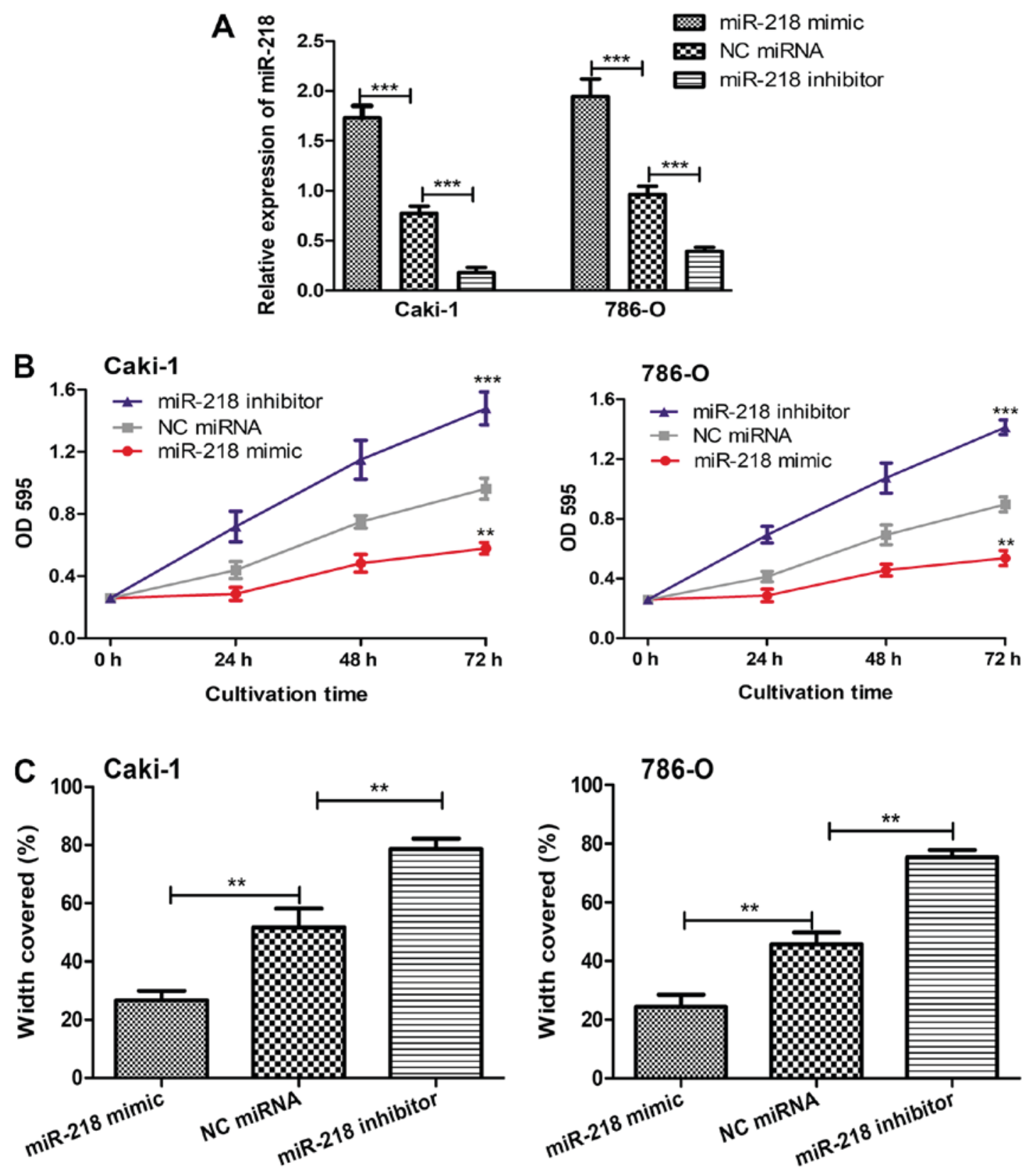

Figure 3. Influence of miR-218 on tumor cell proliferation and migration. (A) Alteration of the miR-218 expression levels in Caki-1 and 786-O cell lines by transfection with miR-218 mimic, miR-218 inhibitor or NC miRNA. ${ }^{* * * *} \mathrm{P}<0.001$. (B) Proliferation of Caki-1 and 786-O cells transfected with miR-218 mimic, miR-218 inhibitor or NC miRNA transfection. ${ }^{* *} \mathrm{P}<0.01$ and ${ }^{* * *} \mathrm{P}<0.001$ vs. NC miRNA. (C) Migration of Caki-1 and 786-O cells transfected with miR-218 mimic, miR-218 inhibitor or NC miRNA transfection. ${ }^{* *} \mathrm{P}<0.01$. Data are presented as the mean \pm standard deviation. miR-218, microRNA-218; NC miRNA, negative control microRNA; OD, optical density.

the collected tissues and a series of cell lines. As presented in Fig. 1A, the expression of miR-218 was significantly lower in ccRCC tissues compared with that in the adjacent non-tumor tissues. Furthermore, miR-218 expression was measured in the human RCC Caki-1 and 786-O cell lines, and in the immortalized proximal tubule epithelial HK-2 cell line. As expected, it was identified that miR-218 expression was significantly lower in Caki-1 and 786-O cells compared with that in HK-2 cells (Fig. 1B).

Low expression of miR-218 is associated with a poorer prognosis. The enrolled patients were classified into two groups, designated high and low, according to the expression level of
miR-218 obtained from RT-qPCR, with a cut-off median value of 1.03. It was revealed that the expression level of miR-218 was significantly associated with tumor size and tumor stage (18), but not with sex and age (Table I). The association between miR-218 expression level and the prognosis of patients with ccRCC was then evaluated. As presented in Fig. 2, the Kaplan-Meier survival curve revealed that patients with low miR-218 expression exhibited a significantly poorer overall survival rate $(\mathrm{P}=0.034)$ compared with those with high expression.

Overexpression of miR-218 inhibits cell proliferation and migration in vitro. To further elucidate the biological role of 
A

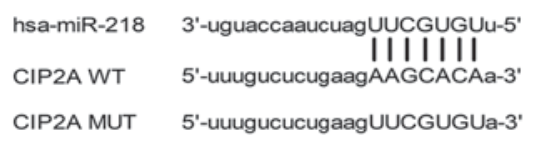

C

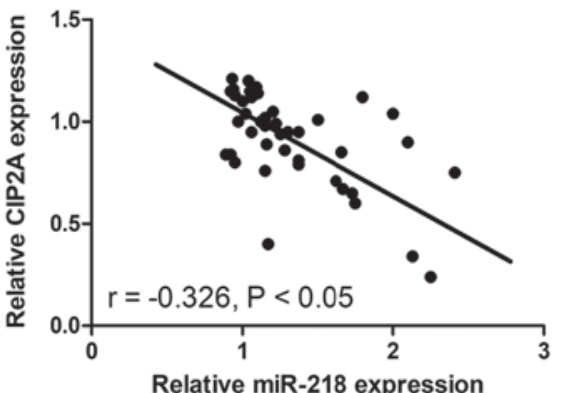

B

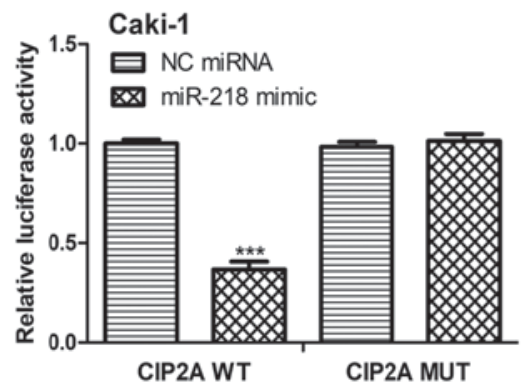

D
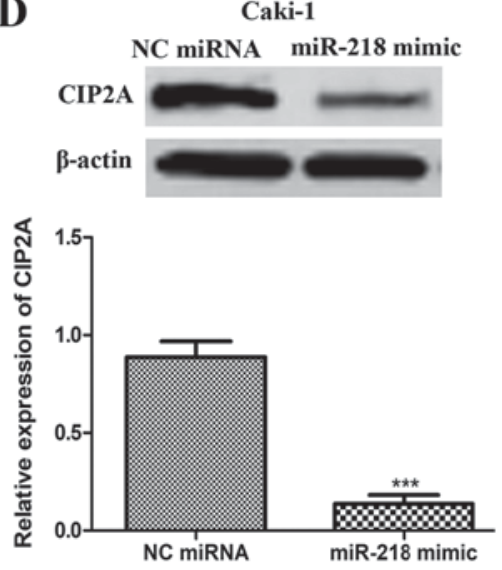

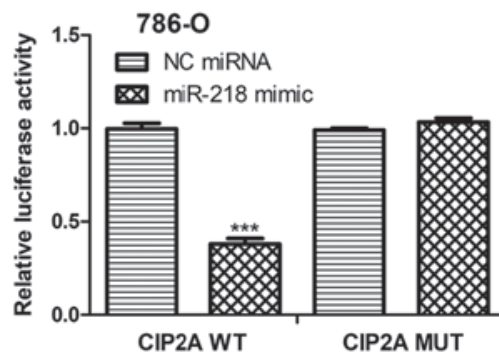

786-O

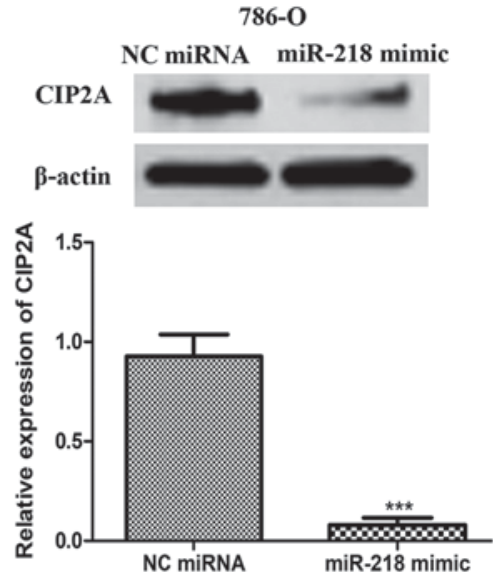

Figure 4. miR-218 inhibits CIP2A expression by specifically targeting its 3'-UTR. (A) Sequence alignment of the CIP2A WT and CIP2A MUT potential miR-218 targeting sites. (B) Luciferase reporter assay demonstrated decreased reporter activity following transfection with the CIP2A WT in Caki-1 and 786-O cell lines overexpressing miR-218. (C) Inverse correlation between miR-218 expression level and CIP2A expression level in ccRCC tissues. (D) Alteration of the CIP2A protein expression levels in Caki-1 and 786-O cell lines transfected with miR-218 mimic or NC miRNA. Data are presented as the mean \pm standard deviation. ${ }^{* * * *} \mathrm{P}<0.001$ vs. NC miRNA. miR-218, microRNA-218; ccRCC, clear cell renal cell carcinoma; UTR, untranslated region; WT, wild-type; MUT, mutant; CIP2A, cancerous inhibitor of protein phosphatase 2A; NC miRNA, negative control microRNA.

miR-218 in ccRCC, gain-of and loss-of function experiments were performed in the selected cell lines. It was confirmed that miR-218 mimic enhanced the expression level of miR-218, while the miR-218 inhibitor reduced the expression level of miR-218 (Fig. 3A). Subsequently, the in vitro cell proliferation and migration abilities of the cells were examined with MTT and wound-healing assays. As demonstrated in Fig. 3B and C, reduced expression of miR-218 significantly enhanced cell proliferation and migration, while induced expression of miR-218 significantly decreased cell proliferation and migration compared with that found in the cells transfected with NC miRNA.

miR-218 directly targets CIP2A. To elucidate how miR-218 inhibits cell proliferation and migration, the TargetScan algorithm was used to predict targets of miR-218. It was identified that CIP2A contains a putative binding sequence for miR-218 (Fig. 4A). A dual-luciferase reporter assay was then used to validate whether CIP2A is a direct target of miR-218. miR-218 significantly inhibited the luciferase activity in cells transfected with CIP2A WT, but not CIP2A MUT (Fig. 4B). Furthermore, an inverse correlation between the expression levels of miR-218 and CIP2A in ccRCC tissues was observed (Fig. 4C). To further confirm that CIP2A is a target of miR-218, the expression level of CIP2A in Caki-1 and 786-O cells transfected with miR-218 mimic or NC miRNA was measured. As expected, miR-218 mimic significantly reduced the protein expression level of CIP2A in the two cell lines (Fig. 4D).
CIP2A functions to promote cell proliferation and migration in vitro. To determine the biological function of CIP2A, a loss-of function experiment was performed by transfecting Caki-1 and 786-O cells with si-CIP2A. The efficiency of knockdown was confirmed by western blot analysis (Fig. 5A). The results of MTT and wound-healing assays revealed that the knockdown of CIP2A significantly reduced the cell proliferation and migration in the two cell lines (Fig. 5B and C). Notably, it was also revealed that the downregulation of CIP2A partly reversed the stimulation effect of miR-218 inhibitor on the proliferation and migration of Caki-1 and 786-O cells (Fig. 5B and C).

\section{Discussion}

ccRCC demonstrates high aggressiveness and is characterized with high rates of mortality and resistance to conventional treatment options, including chemotherapy and radiotherapy (19). In addition, the majority of patients with ccRCC are diagnosed at a late stage and no diagnostic or therapeutic biomarkers for ccRCC are currently available (20). Therefore, the prognosis of ccRCC is relatively poor (20).

A number of studies have demonstrated that miRNAs serve crucial roles in various cellular behaviors, including cell proliferation, apoptosis, migration, tumorigenesis and metastasis $(21,22)$. The value of miRNAs in predicting the prognosis of ccRCC has been appreciated (23). In addition, it has been hypothesized that an improved understanding of the alterations 
A
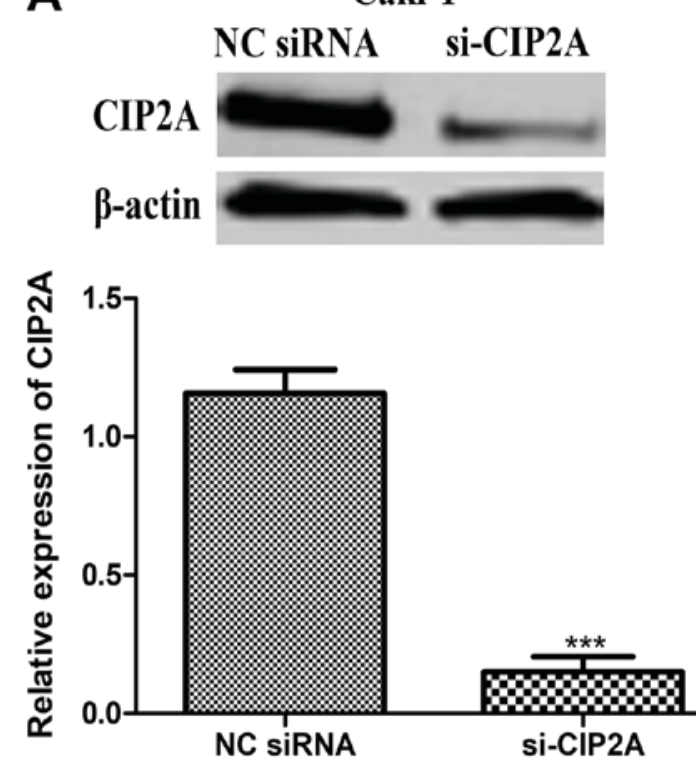

B Caki-1
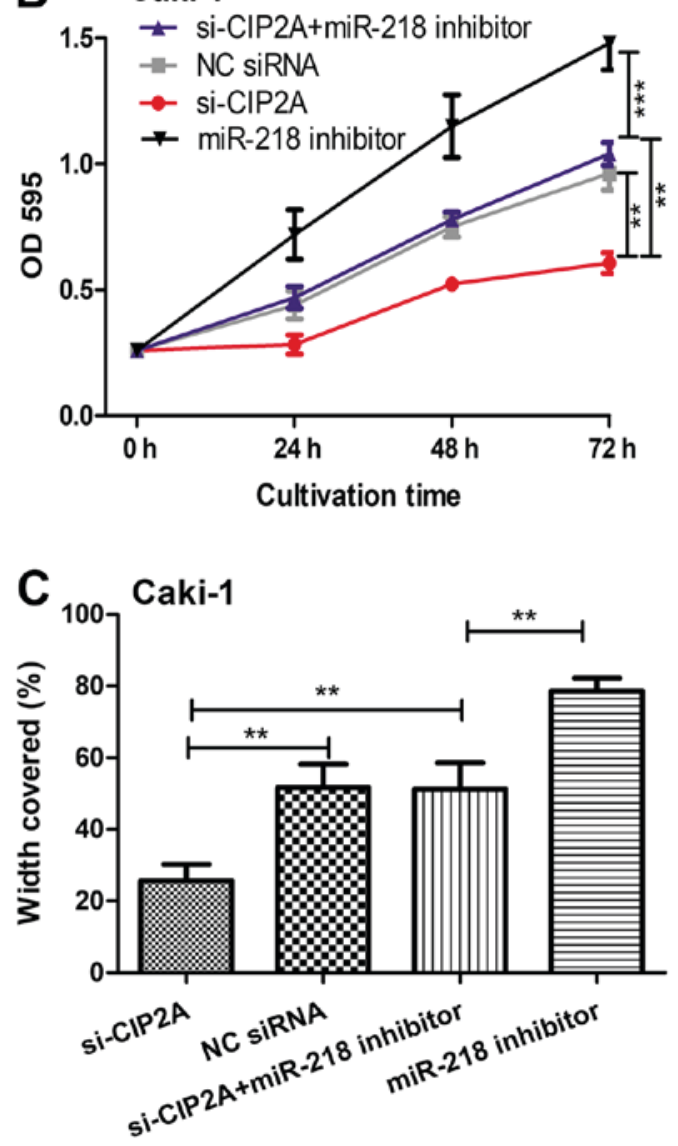

786-0
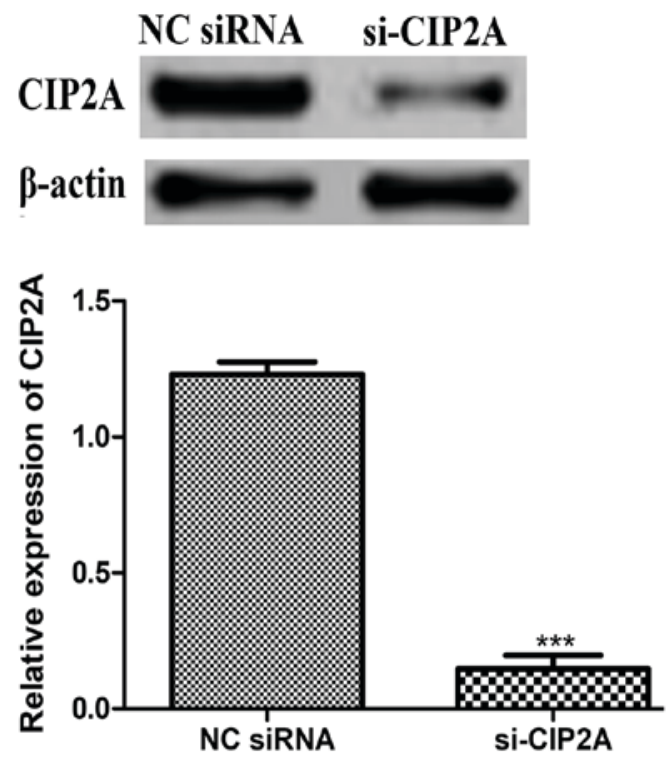

786-0
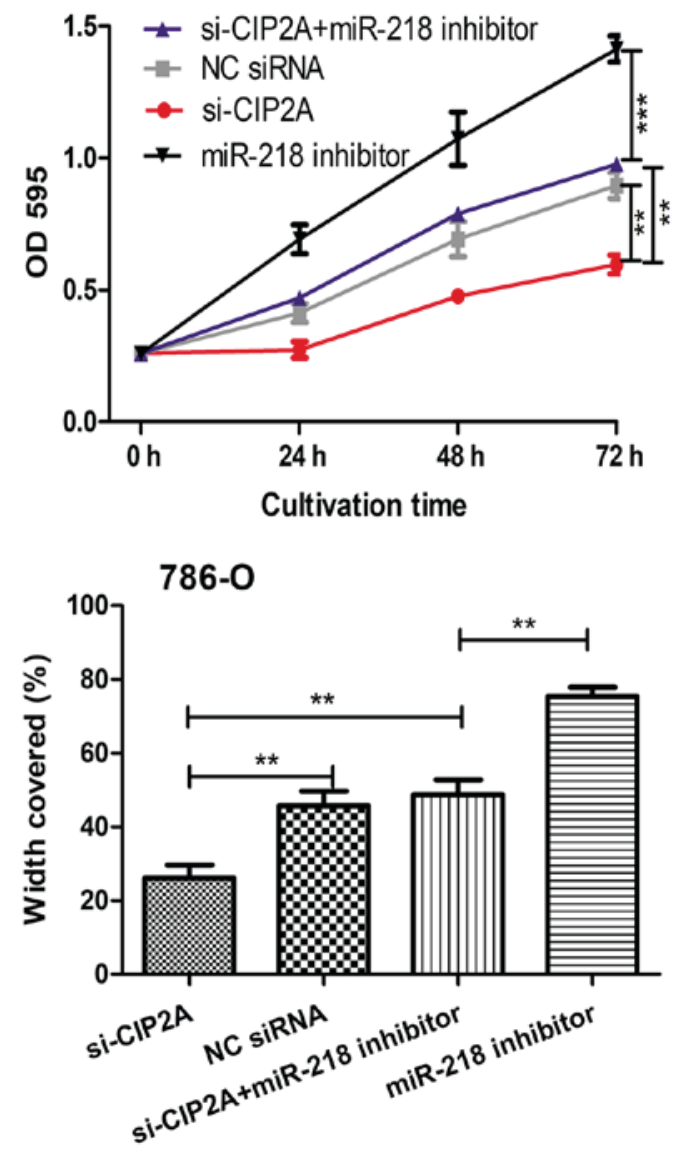

Figure 5. miR-218 regulates the proliferation and migration of ccRCC by targeting CIP2A. (A) Alteration of the CIP2A protein expression levels in Caki-1 and $786-\mathrm{O}$ cell lines transfected with si-CIP2A or NC siRNA. ${ }^{* * *} \mathrm{P}<0.001$ vs. NC siRNA. (B) Cell proliferation and (C) cell migration in Caki-1 and $786-\mathrm{O}$ cell lines transfected with miR-218 inhibitor, si-CIP2A or NC siRNA. ${ }^{* *} \mathrm{P}<0.01$ and ${ }^{* * *} \mathrm{P}<0.001$. Data are presented as the mean \pm standard deviation. miR-218, microRNA-218; NC miRNA, negative control microRNA; ccRCC, clear cell renal cell carcinoma; CIP2A, cancerous inhibitor of protein phosphatase 2A; OD, optical density; si, small interfering.

of miRNA expression in ccRCC may lead to an improved understanding of the mechanisms underlying ccRCC progression, which may provide improvements in the diagnosis and treatment measures for advanced ccRCC (7-9,23).
Downregulation of miR-218 has been reported in multiple types of human cancer (10-15). However, the expression pattern and significance of miR-218 in ccRCC is poorly understood. Therefore, the current study first examined miR-218 
expression in ccRCC tissues, and it was identified that the expression level of miR-218 was lower in ccRCC tissues compared with that in adjacent non-tumor tissues. Low-level expression of miR-218 exhibited a significant association with characteristics of a more aggressive tumor phenotype, including larger tumor size and higher tumor stage. Notably, it was revealed that low expression of miR-218 was associated with a lower 5-year overall survival rate for patients with ccRCC. In functional assays, cell proliferation and migration were significantly suppressed by miR-218 expression. These findings suggest that miR-218 serves a tumor suppressor role in the development of ccRCC.

It is understood that cell proliferation and migration are important hallmarks of malignant tumors (24). Therefore, identification of the underlying molecular mechanisms involved in regulation of ccRCC proliferation and migration is crucial. In the present study, miR-218 targets were predicted to investigate the mechanism underlying the function of miR-218 in ccRCC. Using online predication and luciferase reporter assay, it was revealed that CIP2A may be a target of miR-218 in ccRCC. To support this, it was identified that the expression level of CIP2A was inversely correlated with the expression level of miR-218 in ccRCC, and that CIP2A expression could be negatively regulated by $\mathrm{miR}-218$. Further in vitro functional assays revealed that knockdown of CIP2A reduced cell proliferation and migration. Cell proliferation and migration were lower in cells co-transfected with si-CIP2A and miR-218 inhibitor compared with that in the cells only transfected with miR-218 inhibitor. In summary, these findings indicate that miR-218 exerts its biological function in ccRCC by regulating the expression of CIP2A.

In conclusion, the current study investigated the possible role of miR-218 in ccRCC progression and its underlying mechanisms. The results suggest that miR-218 functions as a novel tumor suppressor by regulating the expression of CIP2A in ccRCC and that miR-218 may be used as a therapeutic target for ccRCC treatment in the future. Although certain novel insights into the mechanisms regarding the progression of ccRCC were provided in the present study, the mechanisms by which miR-218 is downregulated require elucidation in future studies.

\section{Acknowledgements}

Not applicable.

\section{Funding}

This study was supported by the Hebei Province Natural Science Foundation of China (grant no. H2017201052).

\section{Availability of data and materials}

The datasets used and/or analyzed during the current study are available from the corresponding author on reasonable request.

\section{Authors' contributions}

RW, XY, YZ, NJ and TL conceived and designed the experiments. RW, XY, YZ, NJ, TL, WL, HW, GZ and LS performed the experiments. RW and YZ analyzed the data. RW, XY, NJ and TL contributed reagents/materials/analysis tools. RW wrote the manuscript. All authors read and approved the final manuscript.

\section{Ethics approval and consent to participate}

The study was approved by the Ethics Committee of The First Central Hospital of Baoding (Baoding, China). Informed written consent was obtained from all patients who participated in the study.

\section{Patient consent for publication}

Not applicable.

\section{Competing interests}

The authors declare that they have no competing interests.

\section{References}

1. Ljungberg B, Hanbury DC, Kuczyk MA, Merseburger AS, Mulders PF, Patard JJ and Sinescu IC; European Association of Urology Guideline Group for renal cell carcinoma: Renal cell carcinoma guideline. Eur Urol 51: 1502-1510, 2007.

2. White NM, Khella HW, Grigull J, Adzovic S, Youssef YM, Honey RJ, Stewart R, Pace KT, Bjarnason GA, Jewett MA, et al: miRNA profiling in metastatic renal cell carcinoma reveals a tumor-suppressor effect for miR-215. Br J Cancer 105: 1741-1749, 2011.

3. Crispen PL, Breau RH, Allmer C, Lohse CM, Cheville JC, Leibovich BC and Blute ML: Lymph node dissection at the time of radical nephrectomy for high-risk clear cell renal cell carcinoma: Indications and recommendations for surgical templates. Eur Urol 59: 18-23, 2011.

4. Al-Ali BM, Ress AL, Gerger A and Pichler M: MicroRNAs in renal cell carcinoma: implications for pathogenesis, diagnosis, prognosis and therapy. Anticancer Res 32: 3727-3732, 2012.

5. D'Angelo B, Benedetti E, Cimini A and Giordano A: MicroRNAs: A puzzling tool in cancer diagnostics and therapy. Anticancer Res 36: 5571-5575, 2016.

6. Bartel DP: MicroRNAs: Target recognition and regulatory functions. Cell 136: 215-233, 2009.

7. Li M, Wang Y, Song Y, Bu R, Yin B, Fei X, Guo Q and Wu B: MicroRNAs in renal cell carcinoma: A systematic review of clinical implications (Review). Oncol Rep 33: 1571-1578, 2015.

8. Chen X, Wang X, Ruan A, Han W, Zhao Y, Lu X, Xiao P, Shi H, Wang R, Chen L, et al: MiR-141 Is a key regulator of renal cell carcinoma proliferation and metastasis by controlling EphA2 expression. Clin Cancer Res 20: 2617-2630, 2014.

9. Nofech-Mozes R, Khella HW, Scorilas A, Youssef L, Krylov SN, Lianidou E, Sidiropoulos KG, Gabril M, Evans A and Yousef GM: MicroRNA-194 is a marker for good prognosis in clear cell renal cell carcinoma. Cancer Med 5: 656-664, 2016.

10. Tie J, Pan Y, Zhao L, Wu K, Liu J, Sun S, Guo X, Wang B, Gang Y, Zhang Y, et al: $\mathrm{mIr}-218$ inhibits invasion and metastasis of gastric cancer by targeting the Robol receptor. PLos Genet 6: e1000879, 2010.

11. Yu H, Gao G, Jiang L, Guo L, Lin M, Jiao X, Jia W and Huang J: Decreased expression of miR-218 is associated with poor prognosis in patients with colorectal cancer. Int J Clin Exp Pathol 6: 2904-2911, 2013

12. Liu B, Tian Y, Li F, Zhao Z, Jiang X, Zhai C, Han X and Zhang L: Tumor-suppressing roles of miR-214 and miR-218 in breast cancer. Oncol Rep 35: 3178-3184, 2016.

13. Shi ZM, Wang L, Shen H, Jiang CF, Ge X, Li DM, Wen YY, Sun HR, Pan MH, Li W, et al: Downregulation of miR-218 contributes to epithelial mesenchymal transition and tumor metastasis in lung cancer by targeting Slug/ZEB2 signaling. Oncogene 36: 2577-2588, 2017.

14. Li N, Wang LF, Tan GY, Guo ZH, Liu L, Yang M and He J: MicroRNA-218 inhibits proliferation and invasion in ovarian cancer by targeting Runx2. Oncotarget 8: 91530-91541, 2017. 
15. Yang Y, Ding L, Hu Q, Xia J, Sun J, Wang X, Xiong H, Gurbani D, Li L, Liu Y and Liu A: MicroRNA-218 functions as a tumor suppressor in lung cancer by targeting IL-6/STAT3 and negatively correlates with poor prognosis. Mol Cancer 16: 141, 2017.

16. Yu N, Zhang T, Zhao D, Cao Z, Du J and Zhang Q: CIP2A is overexpressed in human endometrioid adenocarcinoma and regulates cell proliferation, invasion and apoptosis. Pathol Res Pract 214: 233-239, 2018

17. Livak KJ and Schmittgen TD: Analysis of relative gene expression data using real-time quantitative PCR and the 2(-Delta Delta C(T)) method. Methods 25: 402-408, 2001.

18. International Agency for Research on Cancer: Tumours of the kidney. In: Pathology and Genetics: Tumors of the Urinary System and Male Genital Organs. Moch H, Humphrey PA, Ulbright T and Reuter VE (eds). 4th edition WHO Classification of Tumors. IARC Press Zurich, Switzerland pp7-10, 2015.

19. De Meerleer G, Khoo V, Escudier B, Joniau S, Bossi A, Ost P, Briganti A, Fonteyne V, Van Vulpen M, Lumen N, et al: Radiotherapy for renal-cell carcinoma. Lancet Oncol 15: e170-e177, 2014
20. Huang QB, Ma X, Zhang X, Liu SW, Ai Q, Shi TP, Zhang Y, Gao Y, Fan Y, Ni D, et al: Down-Regulated miR-30a in clear cell renal cell carcinoma correlated with tumor hematogenous metastasis by targeting angiogenesis-Specific DLL4. PLoS One 8: e67294, 2013.

21. Kloosterman WP and Plasterk RH: The diverse functions of microRNAs in animal development and disease. Dev Cell 11: 441-450, 2006

22. Esquela-Kerscher A and Slack FJ: Oncomirs- microRNAs with a role in cancer. Nat Rev Cancer 6: 259-269, 2006.

23. Ran LJ, Liang J, Deng X and Wu JY: miRNAs in Prediction of Prognosis in Clear Cell Renal Cell Carcinoma. Biomed Res Int 2017: 4832931, 2017.

24. Hanahan D and Weinberg RA: Hallmarks of cancer: The next generation. Cell 144: 646-674, 2011.

This work is licensed under a Creative Commons

Attribution-NonCommercial-NoDerivatives 4.0 International (CC BY-NC-ND 4.0) License. 